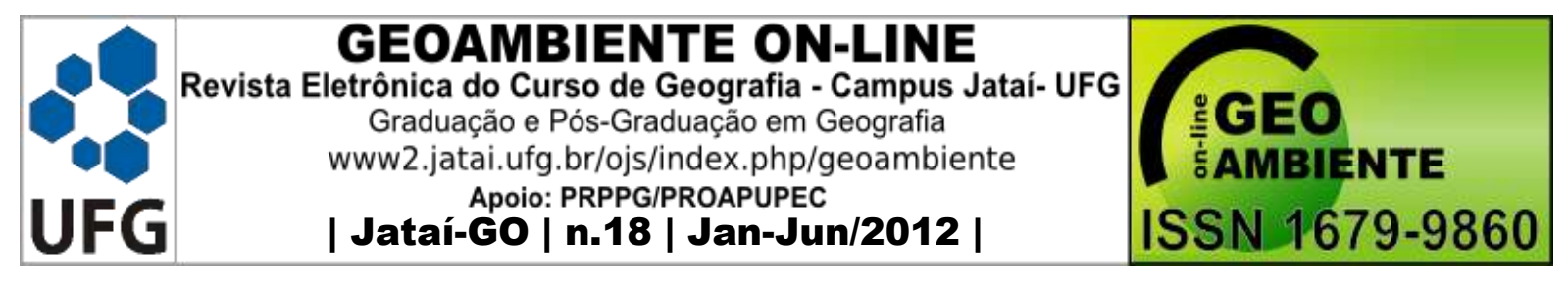

\title{
AGRICULTURA FAMILIAR E MULTIFUNCIONALIDADE NO ESPAÇO AGRÁRIO DE PERNAMBUCO, BAHIA E PIAUí
}

\author{
Irlane Gonçalves de Abreu', Claudio Ubiratan Gonçalves ${ }^{2}$ \\ (1 - Universidade Estadual do Piauí, professora da UESPI, Doutoranda em Geografia pela \\ Universidade Federal de Pernambuco (Convênio DINTER UESPI/UFPE), \\ igascorpion@yaho.com.br, 2 - Universidade Federal do Pernanbuco, Professor do Programa \\ de Pós-Graduação em Geografia, UFPE, birarural@ig.com.br)
}

\section{RESUMO}

A crise do capitalismo em escala global, desencadeada a partir dos anos 1970, vem provocando mudanças no espaço rural brasileiro, cuja característica mais acentuada tem sido a utilização de novas tecnologias nas atividades agrícolas. Esta circunstância tem alterado de forma expressiva o conteúdo social/funções desse espaço, o que tem gerado novas atividades produtivas e novos modos de vida, com destaque para a chamada agricultura familiar e seus desdobramentos, a multi e a plurifuncionalidade. O objetivo deste texto é assim o de discutir transformações sócio-espaciais em diferentes espaços rurais e periurbano brasileiros - Vitória de Santo Antão (Pernambuco), Jeremoabo e Canudos (Bahia) e Teresina (Piauí) - envolvendo as relações e transformações campo-cidade, a partir da prática da agricultura familiar, das multi e plurifuncionalidades a ela relacionadas. Observou-se em visitas a comunidades desses municípios que a agricultura ainda desempenha papel de destaque no mundo rural, da qual os agricultores auferem parte da renda familiar, que, entretanto, é complementada por outras atividades praticadas geralmente em áreas urbana. Este novo rural, apesar das transformações que vem enfrentando, tem na agricultura uma fonte de acesso à terra, às atividades nela desenvolvidas, o que garante às famílias, habitação e alimentação, aspectos igualmente observados nos espaços visitados.

Palavras chave: Renda familiar; Relações cidade-campo; Novo rural.

\footnotetext{
Artigo recebido para publicação em 08 de Janeiro de 2012
}

Artigo aprovado para publicação em 20 de Maio de 2012 


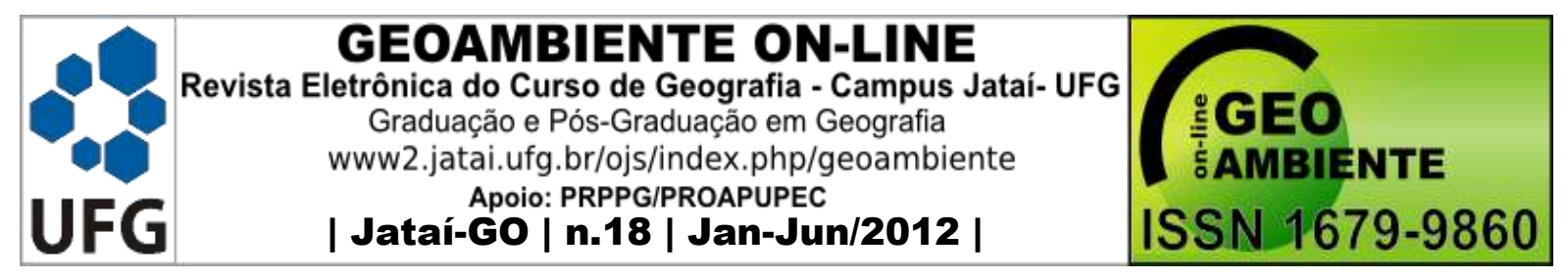

ABSTRACT

MULTIFUNCTIONAL AGRICULTURE AND FAMILY IN THE SPACE AGRARIAN OF PERNAMBUCO, BAHIA AND PIAUI

The crisis of capitalism on a global scale, triggered from the 1970's, has led to changes in the rural areas of Brazil, whose most marked characteristic has been the use of new technologies in agriculture. This circumstance has changed significantly the social content/features of this space, which has generated new productive activities and new ways of life, especially the socalled family farming and its consequences, multifunctional and multi. Based on these ideas this paper intends to discuss sociospatial transformations in different rural areas in Brazil Vitoria de Santo Antão (Pernambuco), Jeremoabo and Canudos (Bahia) and Teresina (Piauí) involving relations and rural-urban transformation, from the practice of family farming, and the multi multifunctional related to it. It was observed in visits to communities of those municipalities that agriculture still plays a major role in rural areas, for which farmers receive part of the family income, which, however, is complemented by other activities practiced usually in urban areas. This new country, despite the changes that have faced, in agriculture has a source of access to land, the activities developed in it, which ensures families, housing and food aspects also observed in areas visited.

Keywords: Familiar income; Relations city-field; New Rural.

\section{RESUMEN}

\section{AGRICULTURA DE LA FAMILIA Y MULTIFUNCIONALIDAD EN LO ESPACIO AGRARIO DE PERNAMBUCO, BAHIA Y PIAUI}

La crisis del capitalismo en escala global, desencadenada a partir de la década de 1970, ha dado lugar a cambios en las áreas rurales de Brasil, cuya más marcada característica ha sido el uso de las nuevas tecnologías en las actividades agrícolas. Esta circunstancia ha alterado de manera significativa el contenido social / funciones de este espacio, que ha generado nuevas actividades productivas y nuevas formas de vida, especialmente en lo que es conocido como la agricultura familiar y sus consecuencias, y plurifuncionalidade múltiplaes. El objetivo de este trabajo es, por lo tanto, discutir las transformaciones socio-espaciales en diferentes espacios rurales y periurbanos brasileños - Vitoria de Santo Antão (Pernambuco), Jeremoabo 


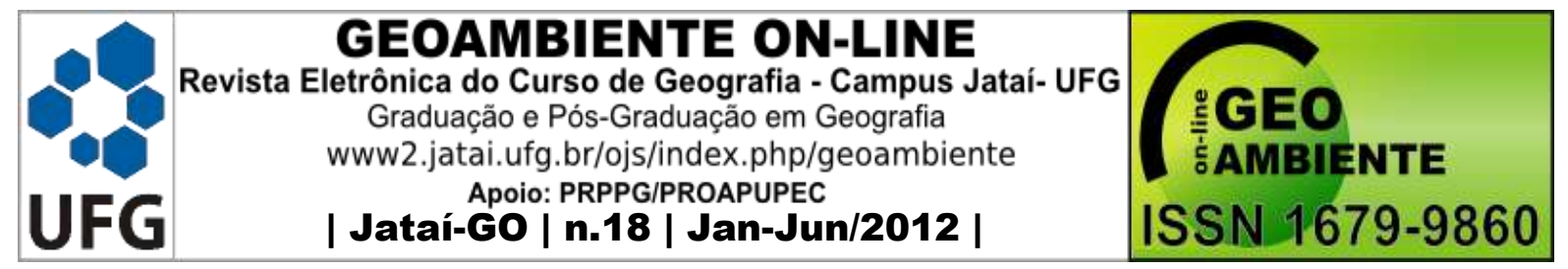

y Canudos (Bahía) y Teresina (Piauí) - involucrando las relaciones y las transformaciones rurales-urbanas, desde la práctica de la agricultura familiar y de las múltiplas y plurifuncionalidades relacionadas con ella. Se observó en las visitas a las comunidades de estos departamentos que la agricultura sigue desempeñando un papel destacado en las zonas rurales, que los agricultores reciben parte de los ingresos familiares, que, sin embargo, se complementan con otras actividades llevadas a cabo por lo general en las zonas urbanas. Este nuevo rural, a pesar de los cambios que ha enfrentado, tiene en la agricultura una fuente de acceso a la tierra, a las actividades desarrolladas en ella, lo que garantiza a las familias, vivienda y alimentación, aspectos que se observa en los espacios visitados.

Palabras claves: Renta de la familia; Relaciones ciudad-campo; Nuevo rural.

\section{INTRODUÇÃO}

Para se compreender as transformações que estão acontecendo no rural brasileiro, é necessário atrelar tais mudanças à crise do capitalismo, em escala global, desencadeada a partir dos anos 1970, em que o padrão de acumulação fordista é substituído por outro, o da economia flexível, o que traz desdobramentos para o modelo de desenvolvimento brasileiro (LISBOA \& CONCEIÇÃO, 1986). É necessário igualmente avaliar o rural, não só como lugar de produção, mas também como espaço de produção e reprodução social de sua população (ELESBÃO, 2007).

Com base nessas idéias observa-se que, a partir da mencionada década de 1970, as transformações mais significativas no rural brasileiro têm como característica mais acentuada o emprego/utilização de novas tecnologias nas atividades agrícolas, o que vem alterando de forma expressiva o conteúdo social/funções desse espaço. Alguns autores, dentre os quais ELESBÃO (2007) e GRAZIANO (1997), chamam essa transformação de modernização da agricultura, processo que não é homogêneo, nem quanto a abrangência espacial nem quanto a forma ou os sujeitos nele envolvidos. Tal processo tem gerado novas atividades produtivas e novos modos de vida, com destaque para a chamada agricultura familiar e seus desdobramentos, a multi e a plurifuncionalidade.

No Piauí, a transformação do espaço rural tem-se dado com mais ênfase em municípios situados a sudoeste do Estado, na região dos cerrados, onde a produção 


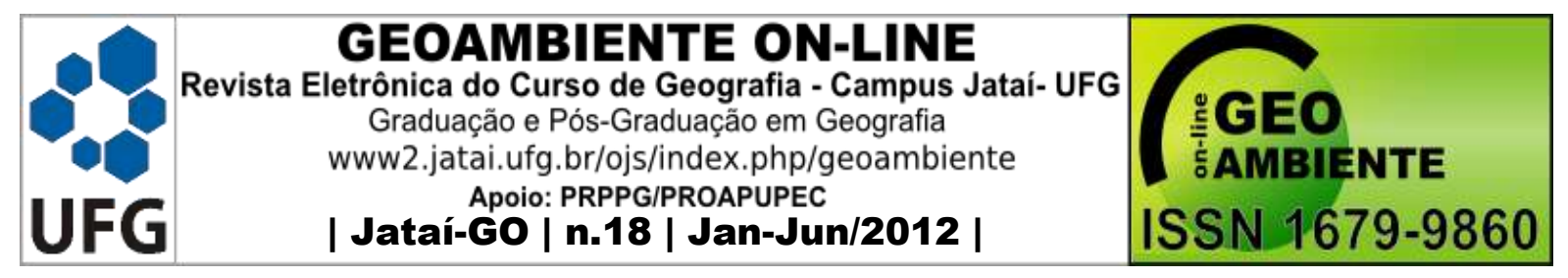

agropecuária em moldes tecnificados vem acomodando uma nova realidade produtiva, profundamente modificadora de espaços e de modos de vida (LEÃO, 2009; GONÇALVES, 2008; SOARES, 2006).

Entretanto, em áreas rurais situadas nas proximidades do urbano estão igualmente ocorrendo alterações, por via também da penetração nesses espaços das relações capitalistas de produção e seus desdobramentos, que apresentam outras características pela forte influência do urbano. É o que parece estar acontecendo em povoados da área rural norte do município teresinense, nos limites da zona periurbana de Teresina, capital do Piaú. Tais alterações têm estimulado a ocorrência de novos usos da terra ou manutenção de antigas formas de produzir, como também têm possibilitado o surgimento de novos tipos de "trabalhadores" e de novos modos de vida, aproximando em características espaços rural e urbano.

Com base em tais premissas, o objetivo deste artigo é apresentar algumas considerações sobre a ocorrência de transformações sócio-espaciais em diferentes espaços rurais e periurbano brasileiros - Vitória de Santo Antão (Pernambuco), Jeremoabo e Canudos (Bahia) e Teresina (Piauí) - envolvendo as relações e transformações campo-cidade a partir das práticas da agricultura familiar, das multi e plurifuncionalidades.

\section{O RURAL, O URBANO E O PERIURBANO: RELAÇÕES E INTERPRETAÇÕES}

A origem da organização dos espaços urbano-rural, ou do campo-cidade, está intimamente ligada à história da sociedade humana, através do trabalho, exercido primeiramente em íntima relação do homem com natureza, quando as atividades produtivas ocorriam num espaço indiferenciado. Tal relação evolui com o passar do tempo para formas mais elaboradas de trabalho e organização social (sociedades antigas tradicionais, sociedade feudal), o que vai permitir o aparecimento de espaços diferenciados - campo e a cidade. O estabelecimento da sociedade industrial, no final do século XIX, caracterizada pelo trabalho humano mediado pela máquina e pelo distanciamento da relação homem-natureza, marca significativamente o papel da cidade numa sociedade complexa e com clara diferenciação dos espaços urbano e rural. (CARLOS, 1990; CARLOS, 1989; SJOBERG, 1972). 


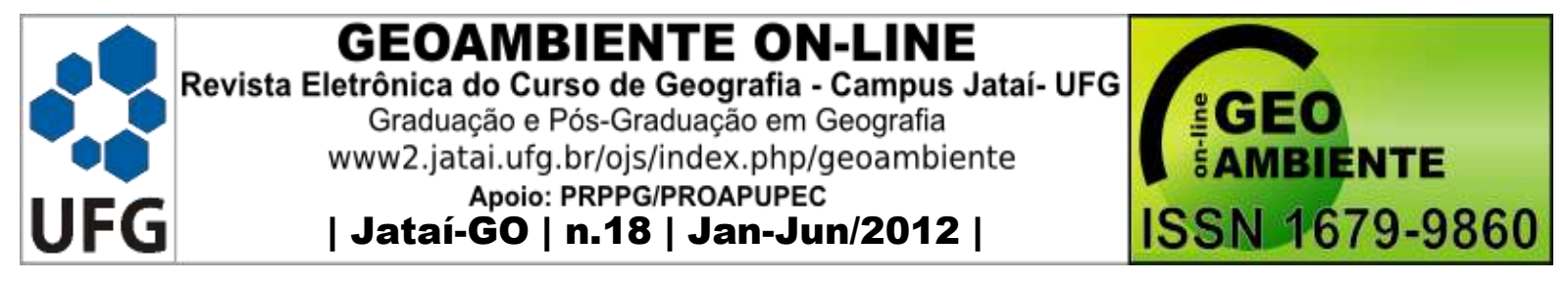

Entretanto, a mesma sociedade industrial que possibilitou a diferenciação entre a cidade e campo, passa, a partir do meio do século $\mathrm{XX}$, por radicais transformações que vão culminar com a emergência do meio técnico-científico-informacional, decorrente dos avanços e da irradiação da técnica por todo o mundo, indiferenciando espaços.

A complexização sócio-espacial daí decorrente leva Santos (2008), a afirmar que "o meio geográfico, que já foi 'meio natural' e 'meio técnico', é hoje, tendencialmente, um "meio técnico-científico". Tal complexização da realidade tem tornado cada vez mais difícil separar, atualmente, o que é rural do que é urbano. Assim, a temática das relações campocidade, bem como dos atores nelas envolvidos, tem sido preocupação constante de diversos estudiosos, especialmente quando se trata de compreender os reflexos e as transformações provocados por tais mudanças.

$\mathrm{Na}$ amplitude das relações cidade-campo merecem reflexão, as transformações que ocorrem tanto nos espaços urbanos quanto nos rurais, como também nos limites do urbano com o rural, nas chamadas áreas periurbanas, transformações que se referem aos aspectos territoriais e aos novos arranjos sociais e econômicos dessas realidades.

Para Candiotto e Corrêa (2008), duas são as concepções mais aceitas sobre a interpretação das relações entre espaços urbanos e rurais: a visão dualista ou dicotômica, para a qual estes espaços se opõem; e a do continuun rural-urbano, que diz que a urbanização tem efeito transformador na sociedade, de um modo geral, e, em especial, no espaço rural, fazendo-o aproximar-se do urbano. Segundo ainda esses autores, mais adaptada à dinâmica espacial contemporânea, a concepção do continuun rural-urbano apresenta duas interpretações: a urbano-centrada, cujo espaço privilegiado é a cidade, apontando para o fim da realidade rural; e outra, que considera que as realidades rural-urbana se aproximam e se integram, sem excluir as particularidades desses espaços e sem representar o fim do rural.

Alentejano (2003), analisando concepções de estudiosos sobre a relação campocidade no Brasil contemporâneo, levanta algumas características sobre a nova dinâmica do campo brasileiro: ser fortemente marcado pela urbanização, de modo que o rural não pode mais ser associado somente à atividade agrícola, como sempre o foi; a importância do segmento familiar; surgimento de ocupações não agrícolas, enquadradas no chamado "emprego refúgio"; bem como a sua precariedade infraestrutural. 


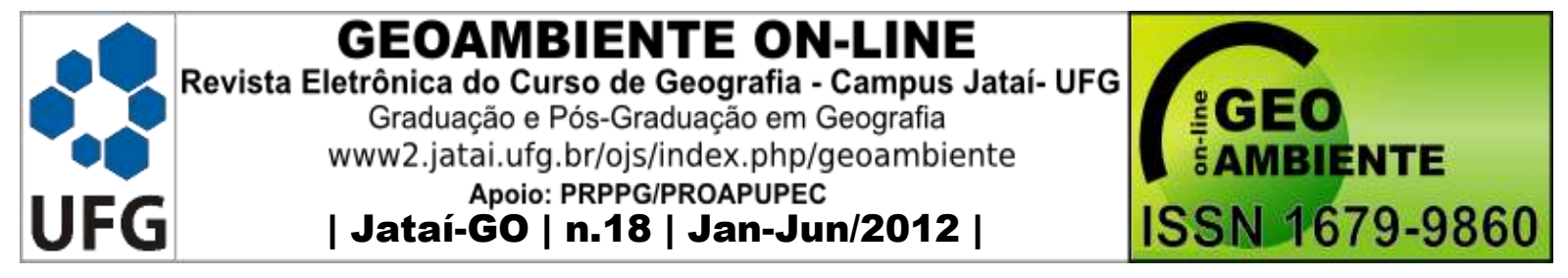

Alentejano (2003), alerta ainda para a fragilidade dos referenciais sobre diferenciação entre o que é urbano e que é rural decorrente da ausência de debate sobre a temática, o que contribui de forma negativa para a indefinição conceitual e de procedimentos legais e administrativos para marcar estas duas realidades, pois também nas interfaces do urbano com rural, nas chamadas áreas/franja periurbana, rurbana ou rural-urbana, verificamse também mudanças muito intensas (MIRANDA, 2008).

A discussão sobre a prevalência/continuidade da espacialidade urbana e/ou rural em áreas periurbanas decorre da imbricação nesse espaço, de processos de natureza espacial (transformações no encontro do rural como urbano, ou no rural mais próximo do urbano), econômica (surgimento de novas atividades no rural, que o estão transformando a ponto de, muitas vezes indiferenciá-lo do urbano) e social (novos comportamentos/modos de vida).

Estudos sobre áreas periurbanas permitem identificá-las e nomeá-las a partir de dois pressupostos básicos e antagônicos - o do continuum rural urbano, cuja matriz está em Lefèbvre (2002), e o da resistência e da capacidade de renovação das atividades rurais e de um consequente renascimento rural, ideia defendida por Kayser (1990) apontado por Miranda (2008) e Wanderley (2005), que discute o renascimento do rural ou o estabelecimento de uma nova ruralidade, afirmando que os termos rural e urbano determinam modos de utilização do território e se aplicam tanto ao espaço como aos indivíduos.

\section{TRANSFORMAÇÕES NO RURAL E EM ÁREAS PERIURBANAS BRASILEIROS}

No contexto das relações cidade-campo aqui referidas, as transformações que vêm ocorrendo no espaço rural bem como em áreas periurbanas brasileiros, têm merecido atenção de diversos estudiosos.

Graziano (1997), diz que, atualmente, o rural não pode ser associado somente à atividade agrícola, como sempre o fora, em razão da dupla urbanização que ocorre no campo brasileiro, de um lado, pela expansão da lógica da produção urbana para os setores modernizados da agricultura, e de outro pela expansão de atividades urbanas para áreas onde a agricultura modernizada não se implantou.

Segundo Rua (2006), a espacialidade do capitalismo contemporâneo requer o entendimento das relações de poder, do exercício da hegemonia e da dialética entre 


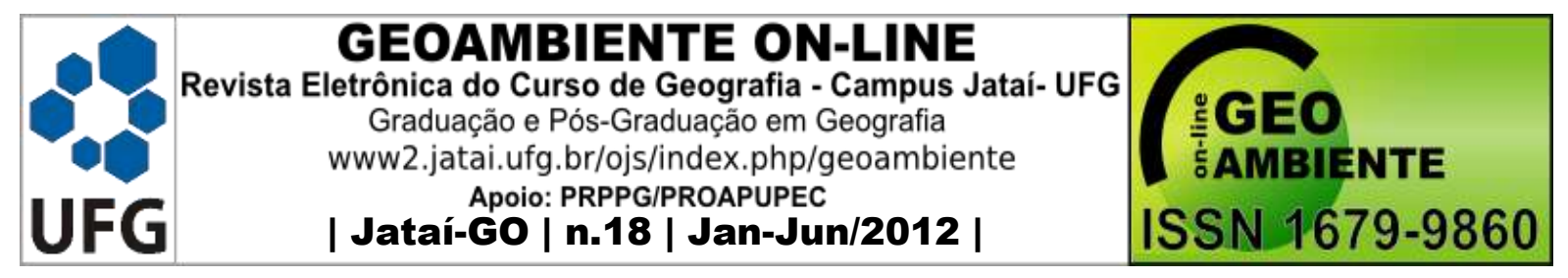

igualização e diferenciação como tendências contraditórias expressas nas interações ruralurbano e suas manifestações, através de aspectos econômicos, políticos, culturais e simbólicos. Desse modo, cidade e campo, urbano e rural são percebidos como polaridades, o que tem mantido a cidade - e o urbano - como dominante na polarização entre esses espaços, e na acentuação de uma dicotomia que, só nas últimas décadas vem sendo alterada por novas lógicas da acumulação capitalista. Como consequência o campo - e o rural - passam a ser percebidos como uma mercadoria capaz de gerar outras mercadorias, além das tradicionalmente relacionadas à exploração da terra rural e ao trabalho a ela incorporado, às quais são atribuídos novos papéis a partir de um movimento de ressignificação do rural. Neste, são valorizados especialmente a natureza e a paisagem do campo resultando, assim, numa recriação do rural.

A partir dessas idéias, Rua (2006), define e analisa as novas interações entre urbanorural, tentando compreender as intrincadas formas de produção do espaço rural, manifestadas em territorialidades híbridas, denominadas por ele de urbanidades no rural.

Para o autor em questão, as transformações ocorridas no Brasil possibilitaram a recriação do rural pelo capitalismo, produzindo novas imagens e dimensões desse espaço, que se torna cada vez mais diferente do agrícola, ao mesmo tempo em que se distinguem cidade e urbano, numa explicitação crescente da complexidade que marca tais relações. Nesse espaço transformado, muitas vezes, a indústria ruraliza-se e os serviços se estendem ao campo, de modo que rural e urbano se fundem, sem, entretanto, tornarem-se uma mesma coisa, já que preservam suas especificidades.

As evidências dessa fusão - as "urbanidades no rural” (Rua 2006), expressam cada vez mais um distanciamento do rural predominantemente agrícola, cujas características são, dentre outras: desaparecimento do predomínio do trabalho agrícola; surgimento de novas atividades, antes exclusivas da cidade; difusão, no espaço rural, do trabalho industrial pela freqüente localização ali de fábricas; distinção da unidade familiar da unidade de produção; envolvimento dos membros da família em prestação de serviços cada vez mais distintos da atividade agrícola, em trabalho fora da unidade produtiva, (tratorista, frentista, comerciário, bancário, veterinário, piloto agrícola, etc); ocorrência de uma sociabilidade mais complexa, que se integra a novas redes sociais; uso de tecnologias alternativas de natureza agroecológica 


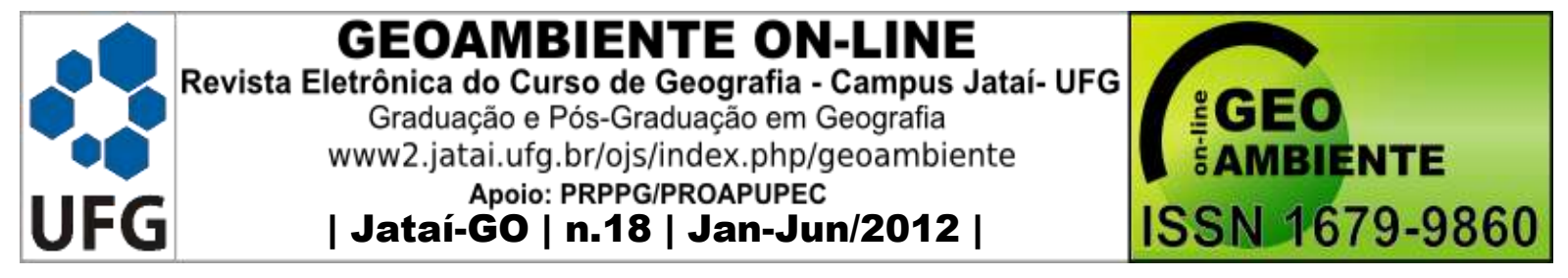

e natural; fortalecimento dos turismos ecológico e cultural, bem como a valorização da cultura local, dentre outras.

Esse processo de revalorização/ressignificação do mundo rural consolida atividades rurais e urbanas em áreas interioranas e influencia as representações do rural, provocando uma revisão conceitual do que é "rural" e do que é "urbano", pois marcam o espaço como um todo.

Rua (2006), enfatiza que a concepção de urbanidades no rural identifica-se com outra, denominada de "novas ruralidades", lembrando, que, em primeiro lugar, a ênfase no rural não pode ser exagerada, pois o urbano parece realmente dominante na relação assimétrica entre urbano e rural e fundamental na construção atual de territorialidades; em segundo lugar, deve ser considerada uma dupla escala de ação: uma, mais ampla, na qual uma urbanização difusa, ideológica e comportamental domina o espaço, e outra, mais restrita, que permite "leituras" particulares de movimentos mais gerais, processados localmente.

Desse modo, a ressignificação do rural, através da idéia de "urbanidades do rural" pode ser analisada a partir de alguns aspectos, citando-se dentre eles: as urbanidades no rural não são apenas novas ruralidades - são o urbano presente no campo, sem que cada espacialidade perca suas características; o espaço híbrido que resulta dessas interações não é um urbano ruralizado nem um rural urbanizado - é algo novo, ainda por definir.

Wanderley (2000), discutindo também o recorte rural-urbano em suas novas e modernas formas, diz que é pertinente analisar os diferentes aspectos espaciais e sociais das sociedades modernas, apontando não para o fim do mundo rural, mas para a emergência de uma nova ruralidade. Para a mencionada autora, essa nova ruralidade é uma construção histórica e seu personagem principal é o camponês, embora não deva ser menosprezada a contribuição de outros atores, (artesãos e demais mediadores da relação cidade-campo) que asseguram, com seu trabalho, a reprodução da autonomia relativa da coletividade local.

Com relação aos espaços periurbanos e suas transformações, por serem áreas de transição rural-urbana, destaca-se como característica a transição do uso do solo urbano para rural, possibilitando uma expansão do urbano que ultrapassa os limites administrativos das nucleações centrais da cidade. Nesses espaços, são frequentes os problemas decorrentes das diferentes dinâmicas da urbanização, como favelização, especulação imobiliária, segregação 


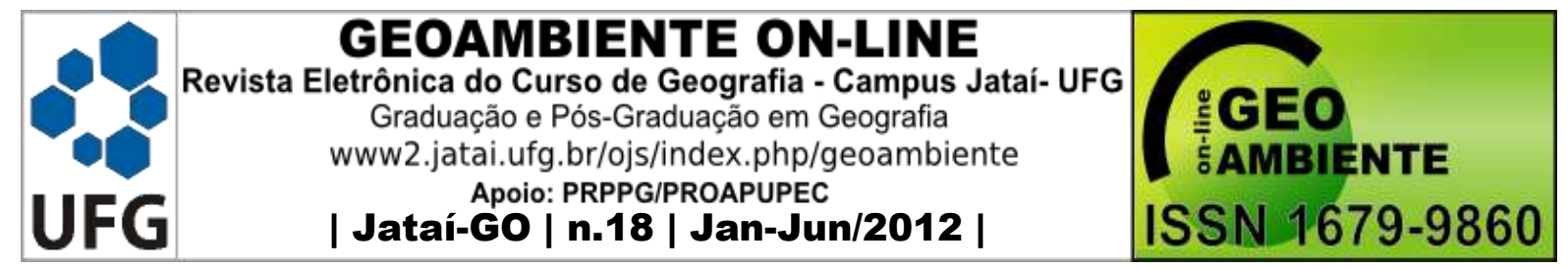

espacial, turismo rural, migrações pendulares, crescimento da economia informal etc., conforme Miranda (2008).

Sobre esta temática Corrêa (2000), informa que os proprietários fundiários agem pressionando o poder municipal para alterar leis de uso e zoneamento do solo, de modo que terras rurais, situadas no limite do urbano e do rural, se tornem espaço urbano, mais valorizado e geralmente demandado por usos residenciais de população de poder aquisitivo elevado.

A heterogeneização do espaço por essas diferentes transformações gera um grande desafio teórico para que se possa compreender este intrincado e complexo processo de "criação de identidades territoriais", seja no que se convencionou chamar de "novo rural", território antes marcadamente agrário, seja em áreas periurbanas, situadas nas proximidade das cidades, tanto pela indiferenciação do próprio espaço, como do comportamento de seus atores e de seu modo de vida.

As idéias até aqui discutidas demonstram que as expressivas transformações ocorridas em espaços rurais e em áreas periurbanas próximas às cidades são consequiência de rupturas econômico-sociais em âmbito global, que têm afetado as relações econômicas e sócio-espaciais das organizações espaciais mundo afora, em especial a partir da segunda metade do século XX.

\section{O NOVO RURAL BRASILEIRO E AS ÁREAS PERIURBANAS: AGRICULTURA FAMILIAR, MULTIFUNCIONALIDADES E PLURIATIVIDADES}

No contexto de organização sócio-espacial do novo rural brasileiro e de áreas periurbanas são incorporadas novas possibilidades de explicação. Assim, para Elesbão (2007), é, entre as décadas de 1950 a 1970 que se desenvolve, em âmbito mundial, o processo de elevação da produtividade da agricultura por meio do uso intensivo de novos fatores de produção: sementes melhoradas, fertilizantes, agrotóxicos, mecanização. Também no Brasil, com o objetivo de modernizar a agricultura, somou-se a esses fatores a concessão de crédito rural.

Ainda conforme Elesbão (2007), o crédito rural subsidiado foi o principal instrumento da "modernização conservadora" da agricultura, que permitiu unir os interesses 


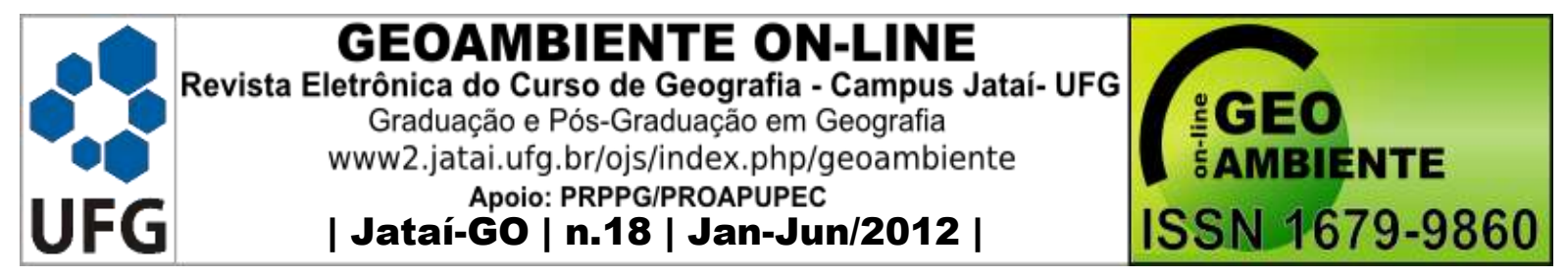

das classes dominantes em torno da estratégia de modernização e possibilitou ao Estado restabelecer seu poder regulador macroeconômico através de uma política monetária expansionista. No final dos anos 60 implantam-se um setor industrial produtor de bens de produção para a agricultura, como também condições para o desenvolvimento de um mercado de produtos industrializados de origem agropecuária. A imbricação entre agropecuária e indústria altera profundamente as relações socioeconômicas no campo, dividindo os agricultores em dois grupos: os que acompanharam esse processo e os que não o conseguiram.

Autores Abramovay (1997); Graziano (1997); Wanderley (2000), discutem, então as repercussões de tais mudanças no campo brasileiro, interpretando-as a partir da concepção de agricultura familiar, associando-a aos agricultores que, de maneiras distintas, inseriram-se no novo processo produtivo.

Schneider (2003), destacando a importância que a agricultura ocupa no espaço rural em regiões e ecossistemas naturais diversos, dá ênfase a mudanças nessa atividade, que vem sendo condicionada/determinada por outras e cada vez mais como uma das dimensões estabelecidas entre sociedade e espaço. Nessa mudança estrutural tem-se como mais expressiva a emergência e expansão das unidades familiares pluriativas, nas quais é cada vez mais freqüente a prática, por meio das famílias residentes no meio rural, de atividades não agrícolas, dentro ou fora da propriedade.

Abramovay (1997), citando Gasson e Errington (1993), destaca seis características básicas da agricultura familiar: a gestão é realizada pelos proprietários; os responsáveis pelo empreendimento estão ligados entre si por laços de parentesco; o trabalho é fundamentalmente familiar; o capital pertence à família; o patrimônio e os ativos são objeto de transferência intergeracional no interior da família; os membros da família vivem no interior da unidade produtiva.

Lembra também Abramovay (1997), que tais características não envolvem julgamento sobre capacidade geradora de renda das unidades produtivas, nem que essas características devam ser encontradas em todos as situações para que uma atividade agrícola seja identificada como agricultura familiar. Esclarece igualmente o autor que a agricultura familiar não pode ser tomada como sinônimo de pequena produção, e que mesmo num país, como o Brasil, marcado pela força do latifúndio e pelo expressivo número de milhões de 


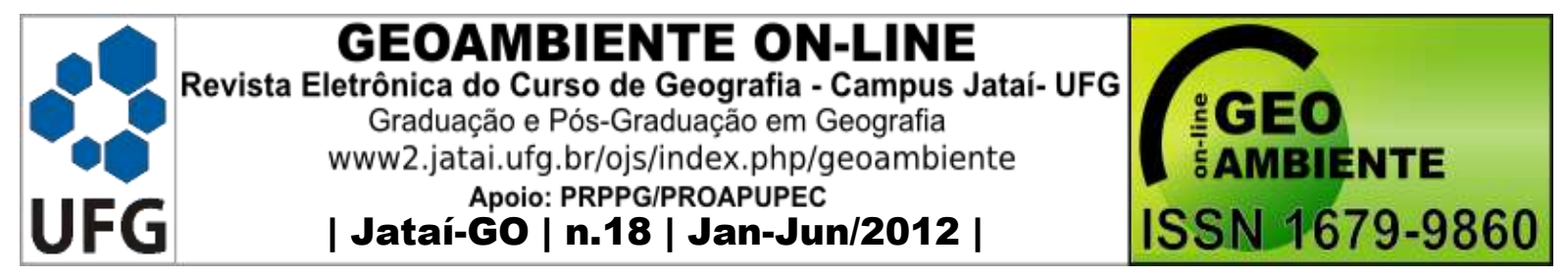

estabelecimentos pequenos, do ponto de vista de sua participação na oferta de produtos agrícolas, existe um segmento importante de agricultores familiares, cuja expressão econômica é muito significativa.

Wanderley (1996), contribui para o debate esclarecendo que agricultura familiar é conceito genérico que incorpora uma diversidade de situações específicas e particulares. É típico das sociedades modernas, adaptando-se a contexto socioeconômico próprio destas sociedades, o que a obriga a realizar modificações importantes em sua forma de produzir e em sua vida social tradicionais.

Ao lado dessas considerações de caráter mais concreto, existem condições que direcionam a discussão sobre o papel da agricultura familiar num plano mais abrangente, destacando-se as que situam essa forma de produção como um dos desdobramentos, ao longo do tempo, do campesinato brasileiro. A esse respeito Wanderley (1996), diz que a agricultura familiar corresponde a uma destas formas particulares de produção constituindo, um modo específico de produzir e de viver em sociedade.

Conforme Neves (2006), a partir da última década do século passado, o termo agricultura familiar ganha destaque, passando a fazer parte do jogo social e político assumido, no Brasil, por pesquisadores de diversas disciplinas e como também pela representação política dos trabalhadores rurais na busca do seu enquadramento profissional, acesso a créditos e assistência técnica, elementos que assegurariam a reprodução de modos de produzir sob a ótica da produção capitalista.

Ainda de acordo com Neves (2006), a definição de agricultura familiar instituída pelo Programa Nacional de Fortalecimento da Agricultura Familiar (PRONAF), é a de "modelo de organização da produção agropecuária onde predominam a interação entre a gestão e trabalho, a direção do processo produtivo pelos proprietários e o trabalho familiar complementado pelo trabalho assalariado", tem o mérito de incorporar conteúdos politicamente construídos, expressando negociações de interesses e conquistas obtidas.

Lembra também Neves (2006), o reconhecimento de que o agricultor familiar, ator da agricultura familiar, raramente se reproduz somente pela atividade agrícola, de modo que a família deve ampliar e qualificar as atividades que já desenvolve e implementar outras atividades agrícolas e não agrícolas, geradoras de renda, adquirindo máquinas, equipamentos 


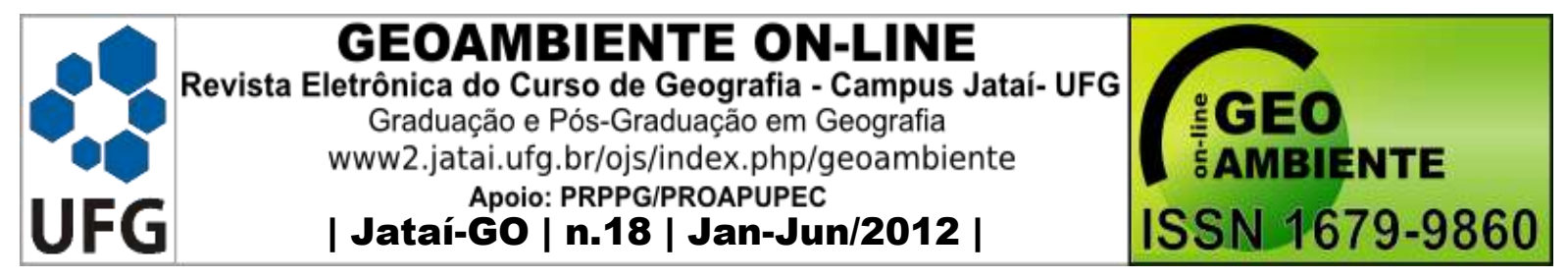

e insumos capazes de ampliar o rendimento da atividade. A autora chama essa diversificação de atividades ligadas à agricultura familiar de poliprodução.

A idéia de poliprodução mencionada por Neves (2006), assemelha-se à de multifuncionalidade, conceito que para Maluf (2003), surgiu para chamar atenção para outras funções além da "função primária" de produzir bens (alimentos e fibras) convencionalmente atribuídas à agricultura.

Valendo-se do conceito em questão Maluf (2003), analisa a realidade rural brasileira em diferentes regiões através das diversas "funções" que a atividade agrícola desempenha na vida familiar do agricultor; das dinâmicas dessa atividade expressas por diferentes territorialidades e da análise de políticas públicas, refletindo a dimensão social da agricultura. Assim, o autor avalia que para as famílias rurais a agricultura continua a desempenar papel primordial como atividade produtiva, desde àquelas que a pratica em condições precárias às que têm na atividade agrícola uma fonte secundária de trabalho e, principalmente, de renda.

Com base nesse pressuposto Maluf (2003), identifica quatro funções relacionadas à multifuncionalidade da agricultura: reprodução socioeconômica das famílias; promoção da segurança alimentar das famílias e da sociedade; manutenção do tecido social e cultural; preservação dos recursos naturais e da paisagem rural, destacando-se os comentários do autor sobre as funções de produção socioeconômica das famílias e manutenção do tecido social e cultural no espaço rural, pela proximidade dos objetivos deste trabalho.

A produção socioeconômica das famílias foi analisada por Maluf (2003), sob o ponto de vista geral, abrangendo atividades complementares, e do ponto de vista restrito, envolvendo a própria atividade principal, enfatizando que, tanto o aspecto mercantil quanto o de autoconsumo familiar favorecem a ocupação territorial, constituindo um dos seus determinantes. No que diz respeito à função de manutenção do tecido social e cultural Maluf (2003), informa que, apesar da atividade agrícola ter perdido centralidade para a reprodução econômica pela via do mercado, de um grande número de famílias rurais, tem, mesmo assim, mantido papel relevante em diversos aspectos da reprodução familiar, como o de possibilitar acesso à terra e às atividades nela desenvolvidas, garantindo-lhes habitação e alimentação.

Diz ainda Mafuf (2003), que a manutenção do tecido social e cultural também é outra função atribuída à agricultura, pois, articulada à função primeira de reprodução 


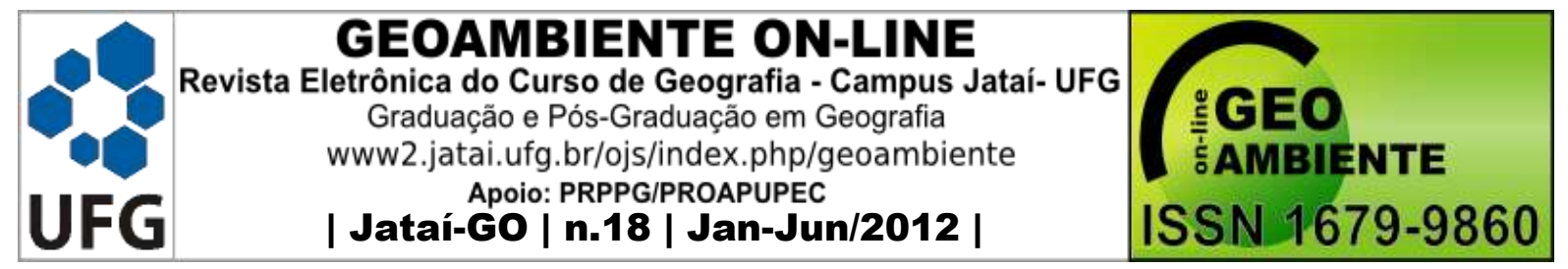

socioeconômica das famílias e de sua segurança alimentar, reforça a identidade social e as formas de sociabilidade das famílias e comunidades rurais, sendo uma das muitas muiltifuncionalidades associadas ao mundo rural.

Analisando também a prática de agricultura familiar brasileira Carneiro (1999), discute o conceito de pluriatividade, que segundo a autora "é uma noção que designa um processo sócio plural, o que significa reconhecer processos pluriativos incorporadores de atividades não agrícolas como constitutivos da própria dinâmica da agricultura familiar".

Agricultura familiar, multifuncionalidade e pluriatividade são aspectos das transformações pelas quais tem passado o espaço rural brasileiro, e que, apesar de intensas, não se apresentam de forma homogênea, nem em termos de espacialização, nem de sua complexidade constituinte. Assim, supõe-se que a própria agricultura familiar se apresente diversificada, dependendo do contexto dos diferentes lugares onde ocorre essa atividade, como também das formas de articulação/imbricação dos atores nela envolvidos e as diversas histórias que lhes dão sustentação.

Conforme Rua (2006), a pluriatividade define uma nova relação com a terra, conceito que se integra a outros, constituindo as chamadas "urbanidades no rural". Tais idéias reforçam o que o mencionado autor já afirmara: na atual fase de reorganização do espaço, especialmente no espaço brasileiro, o que é rural permanece como tal, mas recriado e integrado a novas lógicas produtivas, com base na pluriatividade e na perspectiva de uma multifuncionalidade.

Desse modo, multifuncionalidades e pluriatividades são conceitos recorrentes sobre as novas concepções a respeito do mundo agrário e suas transformações, que passam a incorporar, além do elemento territorial, enquanto base física da produção agrícola como meio de subsistência das famílias, o envolvimento de atores, bem como a dimensão afetiva e simbólica que os camponeses/agricultores desenvolvem com o lugar em que vivem. (MALUF, 2003).

\section{ASPECTOS DA AGRICULTURA FAMILIAR, MULTIFUNCIONALIDADES E PLURIATIVIDADES EM PERNAMBUCO, BAHIA E PIAUÍ}




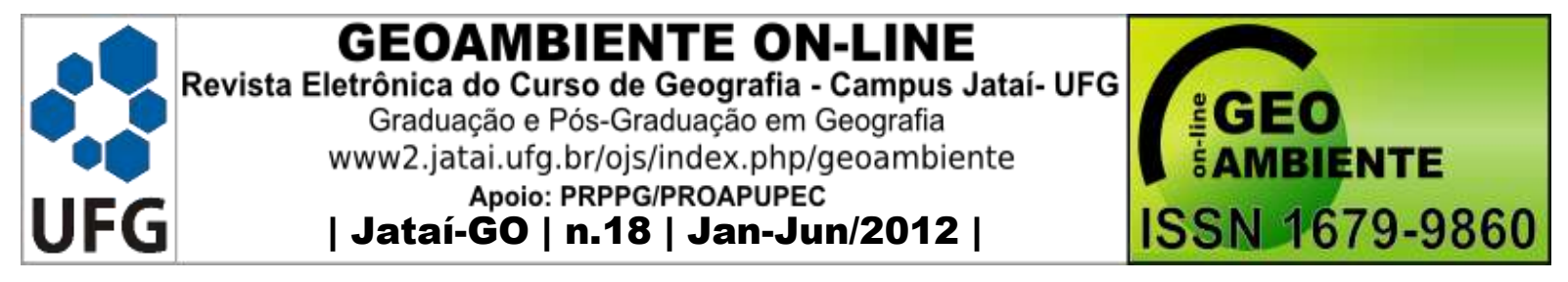

Com base nas idéias até aqui desenvolvidas e em viagem realizada aos municípios de Vitória de Santo Antão (PE), Jeremoabo e Canudos (BA), em junho de 2011, ${ }^{2}$ foram observados aspectos empíricos do ordenamento territorial e ambiental, da organização produtiva e dos modos de vida dos camponeses de comunidades nos mencionados municípios.

Em Vitória de Santo Antão (PE), município situado a $49 \mathrm{~km}$ da cidade do Recife e parte da RM Recife, visitou-se extensa área de produção de hortaliças situada em antigas terras de engenho, onde algumas comunidades organizam-se para produzir e vender seus produtos a atravessadores ou a mercados próximos. A terra onde vivem é propriedade da família (os proprietários são pessoas idosas, que herdaram a terra de antepassados), a força de trabalho é toda familiar (os familiares se envolvem com o trabalho no campo, desde o trato com a terra até a venda do produto). Embora a segunda geração da família (netos) estude em município próximo, colabora nas lides do campo, quando convocada. A residência familiar possui os equipamentos básicos (fogão, geladeira, televisão...), de qualquer família brasileira de renda mediana dos dias atuais e, pela proximidade com as cidades de Recife e Vitória de Santo Antão, os entrevistados demonstram hábitos de consumo dos brasileiros moradores citadinos.

Em comunidades do município de Jeremoabo (BA), cuja sede municipal fica distante $406 \mathrm{~km}$ de Salvador, quilombolas resgataram terras de antepassados e nela organizaram-se em pequenos núcleos, uns, bem distantes da cidade-sede do município, com acesso difícil; outros, em áreas mais próximas da estrada que liga áreas municipais mais povoadas. Nas comunidades visitadas, tanto nas do primeiro tipo, quanto nas do segundo, a agricultura é a atividade principal, que envolve toda a família, e o produto é destinado a consumo próprio.

Com relação a outras atividades ali praticadas, além da lavoura, observou-se que algumas pessoas estão procurando diversificar suas fontes de renda, oferecendo alimento preparado a visitantes que vêm ao povoado para participar de atividades recreativas (que ocorrem geralmente em datas especiais e em fins de semana). O abastecimento de energia é recente, além de precário: somente algumas residências receberam "pontos de luz", de modo que objetos associados ao urbano, como televisão, geladeira, quase não existem. Um dos

\footnotetext{
${ }^{2}$ Viagem de campo em junho de 2011.
} 


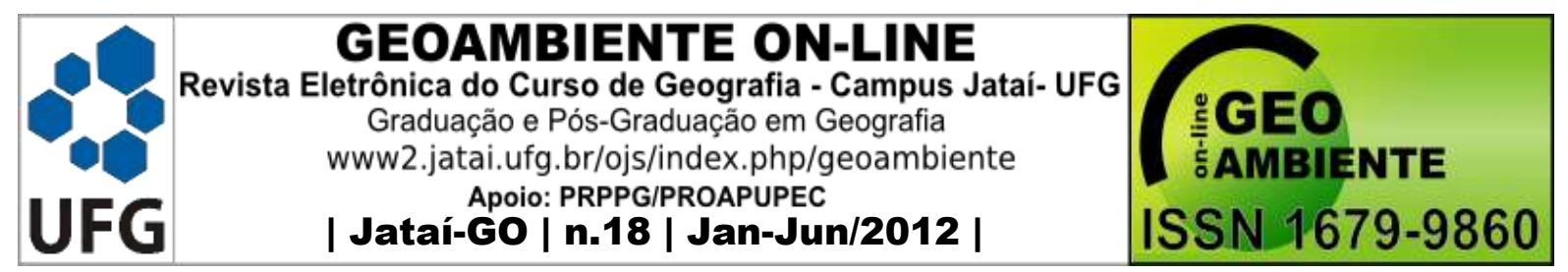

"aspectos fortes" observado nessa comunidade foi a reverência demonstrada ao "patriarca", o senhor mais velho da comunidade, e a necessidade de afirmação de laços de parentesco com ele, como forma de prestígio social.

Em algumas comunidades de Canudos (BA), as famílias de estabelecem numa organização espacial denominada fundo e fecho de pasto, que conforme Alcântara e Germani (1999). São formas de apropriação do território por pastores, lavradores e extrativistas, típicas do semi-árido baiano, onde são praticados criatório de animais e atividades extrativistas, em terras de uso comum, associados à lavoura de subsistência praticada em lotes individuais. São comunidades tradicionais que se autodeterminam e onde prevalecem o direito consuetudinário e os laços familiares.

Na comunidade visitada observou-se que a liderança e as articulações entre os membros comunitários ainda estão se construindo. À época da visita, a comunidade comemorava o dia de São João, quando ficou evidente a influência urbana (pelo menos do urbano ideológico e comportamental, conforme Rua (2006) na comunidade: os visitantes chegavam em motocicletas, as músicas tocadas no alto-falante eram no estilo tecno-brega e forrós urbanos, as comidas servidas eram as de qualquer lanchonete urbana.

No Piauí, as observações resultam de atividades do Programa Institucional de Bolsa de Iniciação à Docência -PIBIC - UESPI 2010-11, ainda em processo, cujo objetivo principal é investigar as transformações que vêm ocorrendo em povoados situados na zona rural norte teresinense nas proximidades da zona periurbana da capital piauiense.

Nos quatro povoados objetos de investigação - São Vicente de Cima, Santa Helena, Morro do Calandi e Campestre Norte - distantes em média $22 \mathrm{~km}$ do centro de Teresina, era área onde, até 20 anos atrás, predominavam atividades associadas à ruralidade (Rua, 2006), como plantios em roças de produtos de subsistência e criatório de animais (Prefeitura Municipal de Teresina, 1995), expressando modo de vida caracterizado por uma relação mais estreita com a natureza. Nesses povoados tem-se observado expressivas mudanças por via da penetração das relações capitalistas de produção, especialmente pela proximidade com o "urbano concentrado" da capital piauiense, através de diversas manifestações, destacando-se o trabalho fora da propriedade rural. 


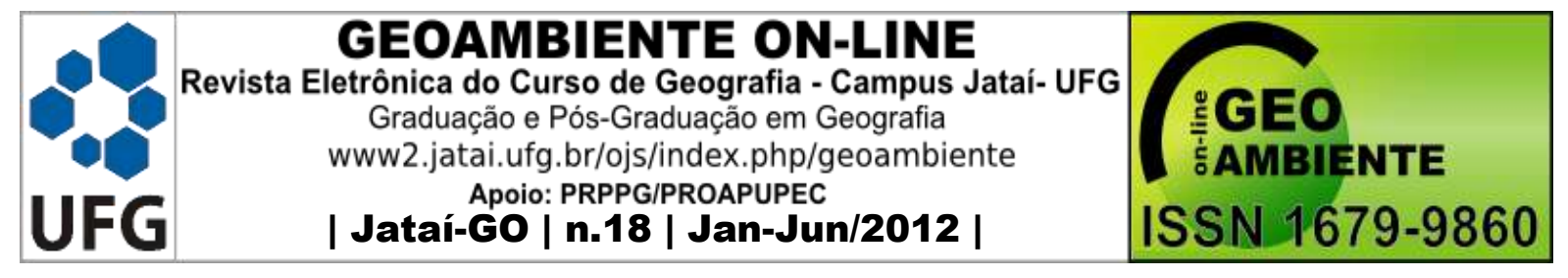

Resumidamente, das 11 famílias entrevistadas nos quatro povoados teresinenses mencionados, $60 \%$, são oriundos do próprio povoado e vivem ali há pelo menos 25 anos; $70 \%$ são proprietários da terra onde vivem e produzem; todos auferem na agropecuária parte do sustento familiar (30\% dedicam-se a agricultura, 70\%, à criação de animais - gado, galináceos, cabras, porcos, pesca e artesanato), complementando com outras atividades, em Teresina, a renda da família, como servidor público, em atividade privada, doméstico, vigia, pedreiro, cortador de cana. Nesta segunda atividade, envolvem-se, primeiramente o pai, seguido da mãe e dos filhos. Todas as famílias se abastecem em Teresina, em bairros próximos à zona rural, deslocando-se através da rodovia PI 112 que liga os povoados à capital piauiense, usando transporte público, bicicleta, motocicleta, automóvel ou carroça. Com relação aos aspectos culturais, todas as famílias participam das festividades do santo padroeiro, embora muitos professem o credo evangélico. Participam também da farinhada, que é momento de congregação das famílias. Quanto às "expressões de vida da cidade”, todas as famílias possuem televisão, geladeira, freezer e telefone celular.

Apesar do limite das informações que dão corpo a este trabalho, é possível dizer que a agricultura familiar é recorrente em todos os espaços visitados, pois conforme Neves (2006), esta atividade tornou-se parte do jogo social e político brasileiro, a partir da última década do século passado.

Considerando-se que a agricultura familiar é uma realidade no universo rural brasileiro e, tomando por referência as características de tal prática apontadas por Abramovay (1997), ela está presente em espaços dos municípios pernambucano, baianos e piauiense visitados, com algumas diferenças, dependendo de espacialidades próprias. Assim, as comunidades em Jeremoabo e Canudos, por estarem mais distantes de áreas urbanas, onde os aspectos naturais da paisagem se sobressaem, a idéia de atividade agrícola corresponde àquela internalizada no imaginário de quem vê empírica e dicotomicamente as relações cidadecampo. Já em Vitória de Santo Antão e no rural/limite com a zona periurbana de Teresina, a presença da cidade atenua a mencionada dicotomia, diluindo os contornos entre o rural e o urbano, aspecto que é mais marcante nos povoados rurais teresinenses analisados.

Apesar da prevalência da atividade agrícola nos espaços visitados, estão presentes outras práticas denominadas de poliprodução conforme Neves (2006), e de pluriatividade 


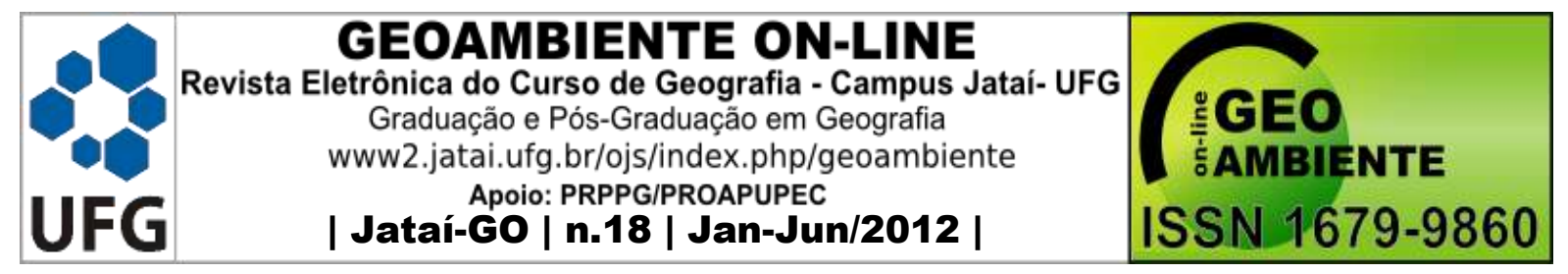

denominações referidas por Carneiro (1999), Rua (2006) e Wanderley (2000), dentre outros, como processo sócio plural que incorpora atividades não agrícolas constitutivas da própria dinâmica da agricultura familiar. Mais uma vez, percebe-se que a maior ou menor proximidade com o urbano nas comunidades/povoados visitados, define diferentes pluriatividades que vão se incorporar à atividade agrícola gerando complemento de renda familiar.

Vale mencionar que Maluf (2003), refere-se a outras funções que ultrapassam àquelas tradicionalmente identificadas com a prática da atividade agrícola, que ele e outros estudiosos denominam de multifuncionalidades da agricultura, destacando-se a possibilidade de acesso à terra e às atividades nela desenvolvidas, garantindo às famílias habitação e alimentação, aspectos igualmente presentes nos espaços visitados.

\section{CONSIDERAÇÕES FINAIS}

- A discussão das transformações das relações campo-cidade, a partir da segunda metade do século XX, é fundamental para a compreensão da dinâmica da sociedade moderna, submetida a transformações de caráter global, na qual o processo de elevação da produtividade da agricultura por meio do uso intensivo de novos fatores de produção, bem como da introdução de aspectos da ciência e da tecnologia nas atividades agrícolas, vêm concorrendo para alterar substancialmente o mundo rural.

- $\quad$ Neste contexto, deve ser enfatizado o papel da agricultura familiar, especialmente na sociedade brasileira, não só por seu aspecto primordial de prover alimentos e local de moradia à família garantindo-lhe habitação e alimentação, como também por constituir elemento definidor de identidades sociais e de padrões de sociabilidade das famílias rurais brasileiras, uma das múltiplas funcionalidades da agricultura, tentativa que foi esboçada neste trabalho, através de investigações preliminares em espaços rurais e periurbanos em Pernambuco, Bahia e Piauí.

- $\quad$ Para finalizar, lembre-se Carneiro (1999), para quem a complexidade do processo de transformação recente do mundo rural brasileiro, heterogênea em suas formas de organização social e de produção, só pode ser compreendida se forem analisadas as relações sociais que definem e redefinem a família, por meio da incorporação de 


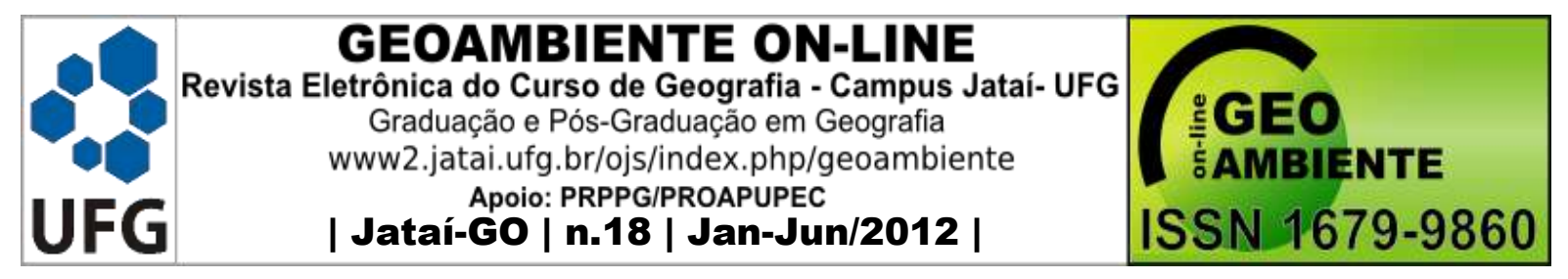

complexas relações sociais que criam e reproduzem valores, através da agricultura familiar.

\section{REFERÊNCIAS}

ABRAMOVAY, R. Agricultura familiar e uso do solo. São Paulo em perspectiva, abril/jun. vol 11, $\mathrm{n}^{\circ} 2:$ 73-78, 1997.

ALCÂNTARA, D. M.; GERMANI, G. I. As comunidades de fundo e fecho de pasto na Bahia: luta na terra e suas espacializações. Revista de Geografia, Recife: UFPE DCG/NAPA, v. 27, n. 1, jan/abr. 2010.

ALENTEJANO, P. R. R. As relações campo-cidade no Brasil do século XXI. Terra Livre, São Paulo, ano 18, v. 2, n.21, p.25-39, jul/dez 2003.

CANDIOTTO, L. Z. P.; CORRÊA, W. K. Ruralidades, Urbanidades e a Tecnificação do Rural no contexto do debate cidade-campo. CAMPO-TERRITÓRIO, Revista de Geografia Agrária, v.3, n.5, p.214-242, fev.2008.

CARLOS, A. F. A. A Cidade, Contexto, São Paulo, 1990. Espaço e indústria, Contexto, São Paulo, 1989.

CORRÊA, R. L. O espaço urbano, Editora Ática, São Paulo, 2000.

COSTA, L. F. C; MOREIRA, R. J.; BRUNO, R. (orgs.) Mundo rural e tempo presente, Mauad, Rio de Janeiro, 1999.

ELESBÃO, I. O espaço rural brasileiro em transformação. Finisterra, LXII, 2007, pp.47-65

Gasson, Ruth e Errington, Andrew - The farm family business - Cab International, Wallingford, 1993.

GONÇALVES, L. G. Estudo de impacto ambiental: Efetividade nos empreendimentos agrícolas do cerrado piauiense? Dissertação apresentada ao Programa Regional de PósGraduação em Desenvolvimento e Meio Ambiente - PRODEMA -TROPEM/UFPI, 2008.

GRAZIANO da SILVA, J. O novo rural brasileiro, Revista Nova Economia, v. 7, n. 1, p. 4381, Belo Horizonte, maio 1997.

KAYSER, B. La renaissance rurale. Sociologie des campagnes du monde occidental. Paris: Armand Colin, 1990. 


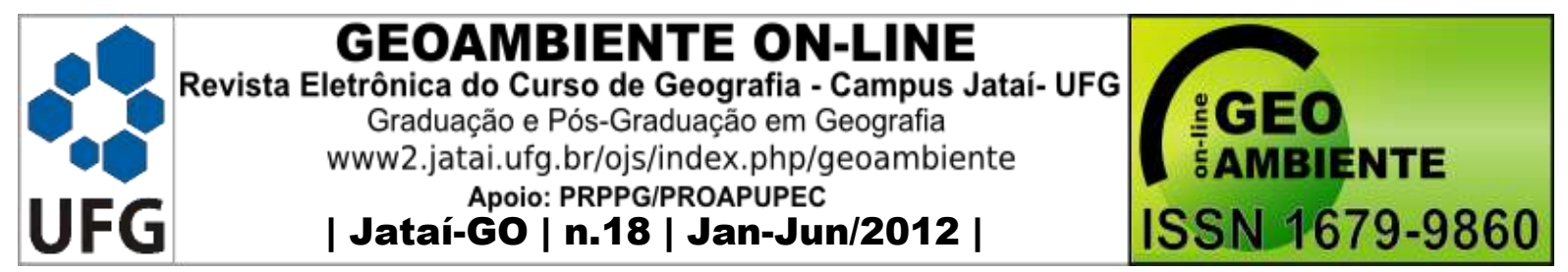

LEÃO, F. J. C. Bacia hidrográfica do rio Uruçui Preto: ocupação e uso do cerrado piauiense. Dissertação apresentada ao Programa Regional de Pós-Graduação em Desenvolvimento e Meio Ambiente - PRODEMA -TROPEM/UFPI, 2009.

LEFÈBVRE, Henry. A Revolução urbana. Belo Horizonte: Editora UFMG, 2002.

LISBOA, J. B.; CONCEIÇÃO, A. L. Desenvolvimento como simulacro do envolvimento: o novo-velho sentido do desenvolvimento e sua funcionalidade para o sistema do capital. Terra Livre, ano 23, v.2, n.29, Ago/Dez/2007, p.115-132.

MALUF, R. S. A Multifuncionalidade da Agricultura na Realidade Rural Brasileira. In: CARNEIRO, M. J.; MALUF, R. S.(orgs.) Para além da produção: multifuncionalidade e agricultura familiar. Rio de Janeiro: MAUAD, 2003.

MIRANDA, L. I. B. de. Produção do Espaço e Planejamento em Áreas de Transição RuralUrbana: o caso da Região Metropolitana do Recife - PE. Universidade Federal de Pernambuco, Programa de Pós-Graduação em Desenvolvimento Urbano, p.334, Recife, Pe, 2008 .

NEVES, D.P. Agricultura familiar: quantos ancoradouros! Niterói, 2006. Inédito. Disponível em: http://www4.fct.unesp.br/nera/usorestrito/Agricultura_Familiar.pdf. Acesso em: 1108201117 hs 34 min.

PREFEITURA MUNICIPAL DE TERESINA. Secretaria Municipal de Agricultura e Abastecimento. Perfil da Zona Rural de Teresina, p.87, 1995.

PROGRAMA INSTITUCIONAL DE BOLSAS DE INICIAÇÃO CIENTÍFICA PBIC UESPI 2010-11 / UESPI. Transformações sócioespaciais na zona rural do município teresinense pela proximidade com a cidade de Teresina. Coordenação Profa. M Sc. Irlane Gonçalves de Abreu.

RUA, J. Urbanidades no rural: o dever de novas territorialidades. Campo-território. Revista de Geografia Agrária. Uberlândia. V. 1, n. 1, p. 82-106, Fev. 2006.

SANTOS, M. Técnica, Tempo, Espaço: Globalização e meio técnico-científico informacional São Paulo, EDUSP: 176p, 2008, 5ed.

SCHNEIDER, S. Teoria Social, Agricultura Familiar e Pluriatividade. Revista Brasileira de Ciências Sociais. Vol. 18, n 15 de fevereiro de 2003. 


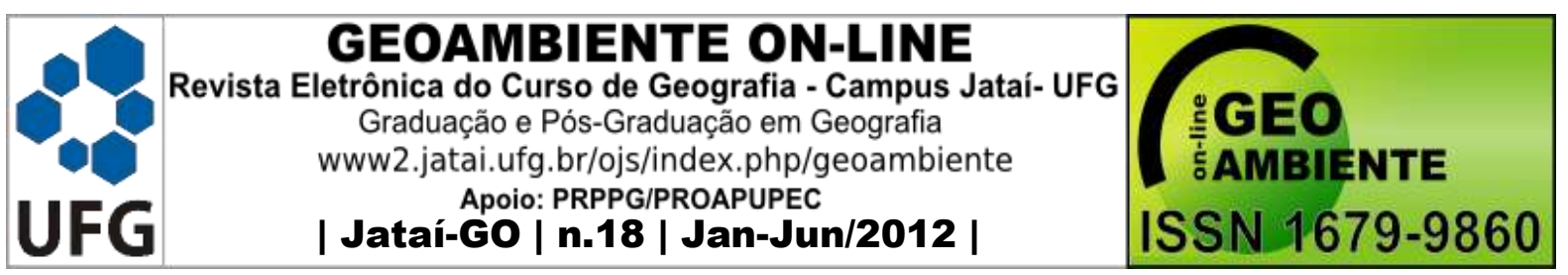

SJOBERG, G. Origem e evolução das cidades. In: DAVIES. K. A urbanização da humanidade. Rio de Janeiro, Zahar, 1972.

SOARES, M. R. Expansão da fronteira agrícola nos cerrados piauienses. (des)territorialização e desafios para o desenvolvimento territorial: o caso do município de Bom Jesus. Dissertação apresentada ao Programa Regional de Pós-Graduação em Desenvolvimento e Meio Ambiente - PRODEMA -TROPEM/UFPI, 2006.

WANDERLEY, M. N. B. Raízes históricas do campesinato brasileiro. XX Encontro Anual da ANPOCS, GT 17, Caxambu, Minas Gerais, outubro de 1996.

. A emergência de uma nova ruralidade nas sociedades modernas avançadas o "rural" como espaço singular e ator coletivo. In. Estudos Sociedade e Agricultura, out. 2000, n.15, Rio de Janeiro, UFRRJ. 